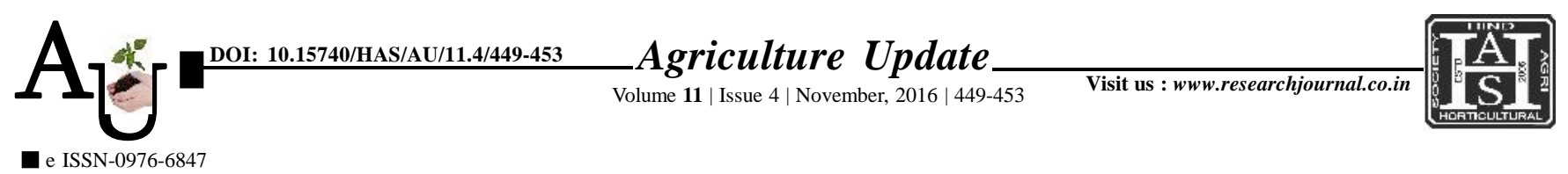

\title{
Research Article: Knowledge of the farmers about soil testing techniques and its recommendations in saline sodic track of Vidarbha
}

\author{
S.S. PATIL, N.M. KALE, D.M.MANKAR AND N.P. JANGWAD
}

Article Chronicle:

SUMMARY : The present study was under taken in Akola, Amravati and Buldana district in Vidarbha

Received :

17.09.2016;

Revised :

08.10.2016;

Accepted :

24.10.2016 region of Maharashtra state. From each selected district one tahsil has been selected purposively where soil is saline or sodic. The selected tahsils are Akola, Daryapur and Shegaon from Akola, Amravati and Buldana districts, respectively. From each tahsil four villages were selected randomly and from each selected village ten farmers were interviewed. Thus, the total 120 respondents were the sample for this study. The objectives of the study were, to study the personal, socio-economic, situational and psychological characteristics of the farmers and to study the knowledge of the respondents about the soil testing techniques and its recommendations in saline sodic track of Vidarbha. The exploratory research design was used for present study. The findings revealed that majority of the respondents

\section{KEY WoRDS :}

Soil testing,

Knowledge,

Extension contact, Socio-economic

Author for correspondence : were in middle age group, educated upto high school level possessed small land holding (1.01-2.00 ha), having agriculture as main occupation, annual income upto Rs. 50,000, farming experience in between 11 to 20 years, medium level of extension contact, they have followed crop rotation on their field, have to travel above $45 \mathrm{~km}$ distance from their village to reach soil testing laboratory, followed seasonal cropping pattern, medium level of motivation and low level of innovativeness. Majority of the respondents having medium knowledge level about soil testing techniques and its recommendations. As regards the relational analysis, age, land holding, occupation, farming experience, crop rotation, distance from soil testing lab and cropping pattern was non-significantly corelated with knowledge. Annual income, extension contact and motivation were significantly correlated with knowledge. Whereas, education and innovation was highly significant with knowledge.

How to cite this article : Patil, S.S., Kale, N.M., Mankar, D.M. and Jangwad, N.P. (2016). Knowledge of the farmers about soil testing techniques and its recommendations in saline sodic track of Vidarbha. Agric. Update,

\section{N.M. KALE}

Department of

Extension Education,

Post Graduate Institute,

Dr. Panjabrao Deshmukh

Krishi Vidyapeeth,

AKOLA (M.S.) INDIA

Email: nmkale1964@

gmail.com

See end of the article for

authors' affiliations 